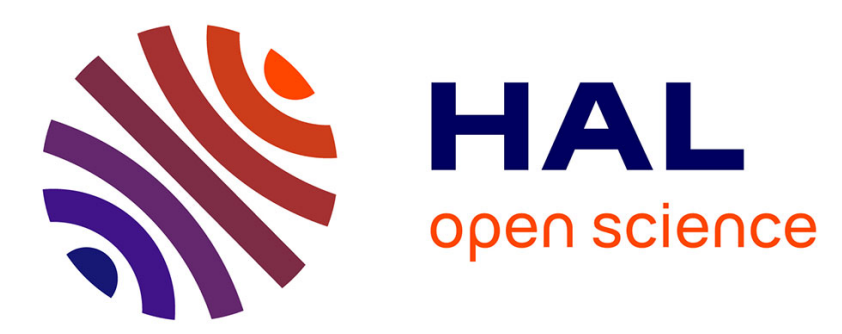

\title{
Analysis of a novel refrigeration Carnot-type cycle based on isothermal vapour compression

\author{
Cyril Toublanc, M. Clausse
}

\section{To cite this version:}

Cyril Toublanc, M. Clausse. Analysis of a novel refrigeration Carnot-type cycle based on isothermal vapour compression. International Journal of Refrigeration, 2008, 31 (7), pp.1190 - 1197. 10.1016/j.ijrefrig.2008.02.008 . hal-01824363

\section{HAL Id: hal-01824363 https://hal.science/hal-01824363}

Submitted on 18 Nov 2019

HAL is a multi-disciplinary open access archive for the deposit and dissemination of scientific research documents, whether they are published or not. The documents may come from teaching and research institutions in France or abroad, or from public or private research centers.
L'archive ouverte pluridisciplinaire HAL, est destinée au dépôt et à la diffusion de documents scientifiques de niveau recherche, publiés ou non, émanant des établissements d'enseignement et de recherche français ou étrangers, des laboratoires publics ou privés. 


\title{
Analysis of a novel refrigeration Carnot-type cycle based on isothermal vapour compression
}

\author{
C. Toublanc, M. Clausse \\ CNAM - IFFI - GP2ES (EA 21), 292 rue Saint-Martin, \\ 75141 Paris Cedex 03, France \\ (+33) (0)1 402720 47, cyril.toublanc@cnam.fr
}

\begin{abstract}
A novel Carnot-type cycle is proposed to allow ideal theoretical performances for sub-critical and trans-critical applications. Three natural fluids, ammonia, carbon dioxide and nitrogen corresponding to one of the application were chosen. Compared to conventional cycles, the Carnot-type cycle leads to COP increase by $4 \%$ to $70 \%$ depending on the application. For the most suitable case $\left(\mathrm{CO}_{2}\right)$, a simpler design resulting from the trade-off between complexity and performances still exhibits high performances (92.5\% of COP $\mathrm{Carnot}_{\text {vs. }}$ 95.4\% for Carnot-type cycle). Compared to conventional one, this simpler design appears to be more sensitive to the expander efficiency but still achieves higher performances: $80 \%$ vs. $50 \%$ of $\mathrm{COP}_{\text {Carnot }}$. The impact of the cooling efficiency was explored too. Considering a compressor temperature pinch equal to $20 \mathrm{~K}$, despites a decrease by $24 \%$ of the COP the performances are still better than those of the conventional one ( $+21 \%$ of COP).
\end{abstract}

\section{Keywords}

Natural refrigerants; Refrigerating system; Compression system; Isothermal compression; Thermodynamic cycle

Nomenclature
\&


Abbreviation

\section{Coefficient Of Performance Internal Heat eXchanger}

\section{Introduction}

In cooling applications, the reverse Rankine cycle, consisting in an isentropic compression, a throttling valve expansion and two isobaric transformations, is mostly used because of practical considerations. Depending on the fluid and heat source temperatures, two main configurations can be distinguished: sub-critical and trans-critical.

Due to evaporation and condensation at constant temperature, reverse Rankine cycle is appropriate for reaching high efficiency with sub-critical cycles. Nevertheless, throttling device and discharged compressor vapour desuperheating, limit its efficiency compared to Carnot cycle. Therefore, designs have been developed to reduce those impacts. Cascades [1] are usually used for very important heat source temperature differences. The disadvantage is to add a temperature pinch in the intermediate heat exchanger. The multi-stage compression is another possibility to achieve better performances. A flash gas bypass is generally used to get a temperature drop between the compressors, meaning that this mass flow fraction is not employed at the evaporator.

The use of an internal heat exchanger (IHX) can be also considered but cannot be generalized with all sub-critical cycles as its interest depends on the fluid [2]. Currently, ejector refrigeration systems are under development [3]. They consist in creating an intermediate pressure to reduce the mechanical power input. Nevertheless, for a given ejector sizing, performances are optimised for nominal operating conditions [4].

The reverse Rankine cycle, as trans-critical cycle, produces important irreversibilities during super-critical gas cooling. However, it is possible to enhance it thanks to an IHX. Indeed, it allows to decrease the optimal high-pressure and the temperature before expansion, which increases cooling capacity, but the mechanical power input too. However, in most cases, cycle performances are enhanced and more particularly with carbon dioxide [5]. Other improvement possibilities are under development. Among them, the ejector system and above all the work-recovering expander could be considered as crucial for trans-critical cycle prospects [6].

In this paper, a new cycle [7] based on isothermal compression is described and compared with sub-critical and trans-critical conventional cycles. From a thermodynamical point of view, it is well-known that the isothermal compression corresponds to the minimal net mechanical work requirement. For attractive cases, a simpler design still including an isothermal compression and an expander, having both efficiencies, is explored. 


\section{Novel Carnot-type cycle description}

The aim of the proposed thermodynamic cycle [7] is to reach Carnot cycle performances between two temperatures called $\mathrm{T}_{\mathrm{LT}}$ and $\mathrm{T}_{\mathrm{HT}}$ (Figure 1). All transformations are taken as reversible when possible.

As the compressor is cooled at the warm heat source temperature, a gas-cooler is not required with trans-critical cycle. However, with a sub-critical cycle and according to technical considerations, the condensation cannot occur inside the compressor, so the heat is rejected successively through the compressor and the condenser.

An ideal IHX is assumed to heat the low-pressure refrigerant vapour from $\mathrm{T}_{\mathrm{LT}}$ to $\mathrm{T}_{\mathrm{HT}}$ when it cools down a fraction of the high-pressure refrigerant from the $\mathrm{T}_{\mathrm{HT}}$ to the $\mathrm{T}_{\mathrm{LT}}$. Only a fraction (x), of the whole mass flow rate, is transferred to the IHX to allow it to reach $\mathrm{T}_{\mathrm{LT}}$. The IHX energy balance settles it.

$$
\mathrm{r}_{\mathrm{CP}} \cdot\left(\mathrm{h}_{7}-\mathrm{h}_{1}\right)+\mathrm{w} \boldsymbol{C P}_{\mathrm{CP}} \cdot \mathrm{x} \cdot\left(\mathrm{h}_{3}-\mathrm{h}_{4}\right)=0
$$

This fluid mass fraction (x) being at the cold heat source temperature, the best thermodynamical way to expand it is the isothermal one. The other mass flow fraction (1-x) is directly expanded from the compressor or the condenser outlet, depending on the cycle configuration, to the evaporator through a reversible adiabatic expander. Then, mechanical work and heat are produced and/or absorbed during expansions and compression.

We then get a Carnot-type cycle, including a reversible isothermal compression, two reversible expansions (isentropic and isothermal), an internal heat exchanger and an optional condenser (isothermal). Assuming the IHX to be ideal, this cycle yields the Carnot coefficient of performance $\left(\mathrm{COP}_{\text {Carnot }}\right)$.

\section{Mathematical model}

In this section, the needed equations for mass and energy balances are presented. All indicated symbols in the following equations must be referred to Figure 1.

\section{- Internal Heat eXchanger}

As seen in section 2, Eq. (1) gives the internal heat exchanger energy balance.

Without any IHX temperature pinch, the exchanger is thermally perfect. Nevertheless, according to the second law of thermodynamics (Eq. 2), all configurations are not possible as some of them result in negative entropy production.

$\mathrm{P}(\mathrm{s})=\mathrm{n} \boldsymbol{\alpha}_{\mathrm{CP}}\left(\mathrm{s}_{7}-\mathrm{s}_{1}\right)+\mathrm{r} \boldsymbol{\mathrm { CP }}_{\mathrm{CP}} \cdot \mathrm{x} \cdot\left(\mathrm{s}_{3}-\mathrm{s}_{4}\right) \geq 0$

Consequently, to keep the isothermal expansion, we propose to reduce the IHX low-pressure outlet temperature $\left(\mathrm{T}_{1}\right)$ until to have no IHX entropy production. As a result, we could not get an isothermal reversible compression.

The input mechanical work and heat extraction during a cooled compression depend on the thermodynamical transformation. To calculate the energy balance on the compressor, either heat transfer phenomena are taken into account [8], or the compression is divided between distinguished unitary compressions including possibly heat transfer assumptions [9]. Here, in order to keep a pure thermodynamical approach, the second solution, without heat transfer phenomena, is retained. 
Then, we consider an endoreversible compression, divided in two serial compressions: an isentropic one allows leading the IHX low-pressure outlet fluid from $\mathrm{T}_{1}$ to $\mathrm{T}_{\mathrm{HT}}$, then the fluid reaches the HP at constant temperature manner.

Herein, this reversible cycle yields the $\mathrm{COP}_{\text {Carnot }}$. However, in most cases, the IHX entropy generation is positive.

Nevertheless, positive or null global entropy generation is not sufficient to affirm that the IHX can run practically. Indeed, we have to verify that it is still accurate locally. The IHX is discretized in finite elements, each exchanging the same heat capacity so that the temperature profiles on the LP and HP sides can be calculated. If the hot stream (HP side here) is always at higher or equal temperature than the cold stream (LP), then the transformation is possible.

Otherwise, $\mathrm{T}_{1}$ must be adjusted to satisfy this condition. Consequently, the cycle is built with an endoreversible compression as previously.

\section{- Compressor (CP) and optional condenser (CD)}

Assuming the isothermal compression to be reversible, without heat losses to the ambiance, yields:

$$
\begin{aligned}
& \&_{\mathrm{CP}}=\mathrm{T}_{\mathrm{HT}} \cdot{ }_{\mathrm{CP}} \cdot\left(\mathrm{s}_{2}-\mathrm{s}_{1}\right) \\
& \&_{\mathrm{CP}}=\mathrm{r}_{\mathrm{CP}} \cdot\left[\left(\mathrm{h}_{2}-\mathrm{T}_{\mathrm{HT}} \cdot \mathrm{s}_{2}\right)-\left(\mathrm{h}_{1}-\mathrm{T}_{\mathrm{HT}} \cdot \mathrm{s}_{1}\right)\right]
\end{aligned}
$$

For sub-critical cycle, the heat rejected at the condenser is given by:

$$
\&_{\mathrm{CD}}=\mathrm{r}_{\mathrm{CP}} \cdot\left(\mathrm{h}_{3}-\mathrm{h}_{2}\right)
$$

\section{- Expanders (E1 and E2)}

The fraction (1-x), of the whole high-pressure mass flow rate at $\mathrm{T}_{\mathrm{HT}}$, enters into an isentropic expansion device, which produces mechanical work.

$$
\mathrm{w}_{\mathrm{E} 1}=\mathrm{n} \&_{\mathrm{CP}} \cdot(1-\mathrm{x}) \cdot\left(\mathrm{h}_{4}-\mathrm{h}_{3}\right)
$$

The fraction (x) leaving the IHX is expanded through an isothermal reversible expander. Heat capacity and mechanical expansion work are given by Eq. (7) and Eq. (8):

$$
\begin{aligned}
& \&_{\mathrm{E} 2}=\mathrm{T}_{\mathrm{LT}} \cdot 1 \mathrm{dP}_{\mathrm{CP}} \cdot \mathrm{x} \cdot\left(\mathrm{s}_{6}-\mathrm{s}_{5}\right) \\
& \mathrm{E} 2_{\mathrm{CP}}^{\mathrm{E}}=\mathrm{r} \&_{\mathrm{CP}} \cdot\left[\left(\mathrm{h}_{6}-\mathrm{T}_{\mathrm{LT}} \cdot \mathrm{s}_{6}\right)-\left(\mathrm{h}_{5}-\mathrm{T}_{\mathrm{LT}} \cdot \mathrm{s}_{5}\right)\right]
\end{aligned}
$$

Mechanical power from each expander is recovered, so that the net compressor input power is:

$$
\begin{gathered}
\mathbb{N E T}_{\mathrm{CP}}^{\&}-\left|W_{\mathrm{E} 1}^{\&}\right|-\left|W_{\mathrm{E} 2}^{\&}\right| \\
- \text { Evaporator (EV) }
\end{gathered}
$$

The two-phase flow rate coming from E1 and saturated liquid coming from E2 enter the evaporator at the same temperature $\mathrm{T}_{\mathrm{LT}}$. The evaporator outlet is taken as saturated vapour at $\mathrm{T}_{\mathrm{LT}}$. Then, the evaporator cooling capacity is given by: 


$$
\mathcal{Q}_{\mathrm{EV}}=\mathrm{r}_{\mathrm{CP}} \cdot\left(\mathrm{h}_{7}-\mathrm{x} \cdot \mathrm{h}_{6}-(1-\mathrm{x}) \cdot \mathrm{h}_{4}\right)+\&_{\mathrm{E} 2}
$$

Here, the heat capacity absorbed by the expander $2\left(\&_{\mathrm{E} 2}\right)$ is used to increase liquid quality at the evaporator inlet.

The corresponding $\mathrm{COP}_{\mathrm{Carnot}}$ and the cycle $\mathrm{COP}$ are given by:

$$
\mathrm{COP}_{\mathrm{CARNOT}}=\frac{\mathrm{T}_{\mathrm{LT}}}{\mathrm{T}_{\mathrm{HT}}-\mathrm{T}_{\mathrm{LT}}} \text { and } \mathrm{COP}=\frac{\mathcal{Q}_{\mathrm{EV}}}{{ }_{\mathrm{NET}}}
$$

All thermodynamical properties were calculated with Refprop7.

Three different cycle configurations are considered: a sub-critical, a trans-critical and a cryocooler cycles. Each of them uses a natural refrigerant: ammonia, carbon dioxide and nitrogen respectively. The revival of ammonia and particularly carbon dioxide is due to environmental preoccupations: ozone layer depletion and above all greenhouse gases emissions.

\section{Sub-critical cycle}

Because of its high temperature overheating during compression, ammonia was chosen. Hence, the expected benefit of isothermal compression should be more noticeable than with hydrocarbons or fluorine gases.

A Carnot-type ammonia sub-critical cycle operating between $40^{\circ} \mathrm{C}$ and $-20^{\circ} \mathrm{C}$, corresponding to refrigeration applications, is considered (Figure 2). With given operating conditions, an ideal IHX cannot be achieved without temperature pinch and the calculated temperature profiles are thermally appropriate.

Our novel Carnot-type performances are compared with that of usual ammonia refrigeration cycle (A) made of an adiabatic reversible compressor, a throttling device, a condenser without sub-cooling and an evaporator without super-heating. Furthermore, we consider another similar design equipped with an expander (B) instead of a throttling device.

The comparison results are reported in Table 1.

With these operating conditions, the performances of the Carnot-type cycle are very close to Carnot ones $(99.8 \%)$. It proves that IHX irreversibilities are negligible.

Compared with the conventional design (A), the novel cycle performances improvement is above $20 \%$. However, considering a conventional cycle with an expander (B), our proposed cycle enhancement reaches only $12 \%$.

Table 1 highlights the fact that volumetric capacity is reduced by more than $10 \%$ with the Carnot-type cycle compared with the conventional design. This reduction is the consequence of compressor sucked vapours density and specific cooling energy deviations. Indeed, the Carnot-type cycle mass flow split allows increasing the inlet evaporator liquid quality and consequently the specific cooling capacity by $15 \%$ and $11 \%$ compared to conventional cycles (A) and (B) respectively. In the other hand, the Carnot-type cycle compressor sucked vapour is superheated and its density decreases by 
$27 \%$. As a result, the density drop being more important than the specific cooling capacity increase, the volumetric capacity decreases.

It has to be noticed that the Carnot-type cycle needs to reject less heat than conventional cycles $(-6 \%$ and $-3 \%)$. However, the difference is minimal as the rejected heat contribution during the compression (Carnot-type cycle) or the desuperheating (conventional cycles) is quite similar and small as they are equal to 35\% and $24 \%$ respectively of the latent heat rejected during condensation.

Lastly, the expansion work recovery gain represents less than $10 \%$ for both cases; this poor contribution is due to liquid properties at the expander inlet. That is particularly true with Carnot-type cycle as half of the mass flow rate has to be isothermally expanded to get close to $\mathrm{COP}_{\text {Carnot }}$.

Despite important ammonia vapour superheating during compression, the Carnot-type cycle, or more generally the isothermal compression, interest seems limited (COP increased by $10 \%$ ). Calculations were made with propane and $\mathrm{R}-134 \mathrm{a}$ at previous operating conditions: the Carnot-type cycle gain is less than 1\%. Hence, the Carnot-type cycle no interest might be generalized for all sub-critical cycles, conventional cycles having already high performances.

\section{Trans-critical cycle}

The carbon dioxide used as refrigerant in air-conditioning applications is currently under development. Research programs have brought $\mathrm{CO}_{2}$ mobile air-conditioning systems at a competitive level with hydrofluorocarbons ones in spite of its poor thermodynamic characteristics. Indeed, because of $\mathrm{CO}_{2}$ low critical point $\left(31^{\circ} \mathrm{C}, 73 \mathrm{bar}\right)$ the $\mathrm{CO}_{2}$ cycle is often trans-critical. Here, the $\mathrm{T}_{\mathrm{HT}}$ is still equal to $40^{\circ} \mathrm{C}$ and $\mathrm{T}_{\mathrm{LT}}$ is set at $0^{\circ} \mathrm{C}$.

In this section, the Carnot-type cycle is compared to the $\mathrm{CO}_{2}$ conventional one with recovering of expansion work (Figure 3). As trans-critical cycles are sensitive to the high-pressure, the influence of this parameter is addressed on Figure 4.

To operate properly the Carnot-type cycle, the outlet isentropic expander refrigerant has to be saturated vapour or liquid-vapour mixture. In consequence, the high-pressure has to be higher than 60 bar to match this requirement. The temperature profiles along the IHX were calculated as explained in section 3 . They are reported as $T_{H P} v s . T_{L P}$ on Figure 5.

From the calculations, it appears that the high-pressure must be higher than 78.5 bar to operate normally the cycle. At lower high-pressure, an endoreversible compression is used achieving $\mathrm{COP}_{\text {Carnot }}$.

The following results are done above 78.5 bar and the deviation with $\mathrm{COP}_{\text {Carnot }}$ is only due to the IHX irreversibilities. For example, Figure 2 depicts a Carnot-type cycle operating at 100 bar.

For the proposed system (B - Figure 4), the performances are always higher than the conventional design (A - Figure 4 ) and close to $\mathrm{COP}_{\text {Carnot. }}$. For conventional trans-critical cycle, an optimal high-pressure exists at approximately 92.5 bar corresponding to a COP equal to 3.83. For the new design cycle, no optimal high-pressure is noticed in the high-pressure studied scale. However, the coefficient of 
performance tends asymptotically towards $\mathrm{COP}_{\text {Carnot }}$ when increasing the high-pressure ( $98 \%$ of $\mathrm{COP}_{\text {Carnot }}$ at 150 bar).

Table 2 shows some important figures for a high-pressure set at 92.5 bar corresponding to the optimal performance of conventional cycle.

Performances are greatly improved, (70\% at 92.5 bar), without changing significantly the refrigerating effect per unit of swept volume. Unlike ammonia, the $\mathrm{CO}_{2}$ Carnot-type cycle improves the volumetric capacity. Indeed, as trans-critical cycle has an internal heat exchanger, the compressor inlet is fixed; the volumetric capacity depends only on specific cooling capacity and not on suction density. So, $\mathrm{CO}_{2}$ isothermal compressors, as well as conventional ones, keep the advantage to be smaller than corresponding hydrofluorocarbon compressors.

Unlike sub-critical cycle, expansion energy recovering is relevant to trans-critical cycle. It is particularly true with proposed design, as it represents approximately half net-mechanical work against $25 \%$ with the conventional case. Indeed, the mechanical power input is minimal with an isothermal compression and despite the lower mass flow fraction expanded through E1 (Figure 1) work recovered during expansion is similar to the conventional cycle one.

Lastly, the Carnot-type cycle rejects approximately $7 \%$ less heat than the conventional cycle.

For a high-pressure set at 92.5 bar, Carnot-type gain is substantial compared with the state of the art conventional cycle. Furthermore, as the high-pressure increases, benefit is growing too.

\section{Cryocooler cycle}

In this section, heat source temperatures correspond to nitrogen liquefaction applications. $\mathrm{T}_{\mathrm{HP}}$ is still equal to $40^{\circ} \mathrm{C}$ while $\mathrm{T}_{\mathrm{LP}}$ is equal to $-195^{\circ} \mathrm{C}$ corresponding to the atmospheric saturation temperature.

With the Carnot-type cycle, whatever the high-pressure in the studied scale (40 bar to 200 bar), the two-temperatures Carnot-type cycle yields to negative entropy production at the IHX. Then, we have to consider the endoreversible compression by reducing $\mathrm{T}_{1}$ ($67^{\circ} \mathrm{C}$ at 40 bar and $+13^{\circ} \mathrm{C}$ at 200 bar). Consequently $\mathrm{COP}$ is always equal to $\mathrm{COP}_{\text {Carnot }}$.

Claude-type cycle is the reference liquefaction cycle. With ideal expansion processes, only an expander and two IHX are required. One, assumed perfect because of the different mass flows in each side, allows limiting considerably irreversibilities of the second IHX. At 40 bar, which is approximately the practical operating high-pressure, the Claude-type cycle reaches around $96 \%$ of $\mathrm{COP}_{\text {Carnot }}$.

In conclusion, possible profit does not seem significant (4\%). Indeed, cycles are quite similar as based on compression cooling. 


\section{Impact of design and components efficiency on trans-critical cycle performances}

As seen, the profit due to Carnot-type cycle depends on the application. With the sub-critical or the cryocooler cycle, a profit exists, but is small compared with the $\mathrm{CO}_{2}$ trans-critical cycle.

Hence, we will only focus on $\mathrm{CO}_{2}$ trans-critical cycles degradations. Three types of degradations are studied:

- cycle design,

- expander efficiency,

- compression cooling efficiency.

\subsection{Cycle design}

A simpler design (Figure 6), being a trade off between complexity and performances but still based on an isothermal compression, is proposed [10]. It offers high performances (Table 3): COP already reaches $87 \%$ of $\mathrm{COP}_{\text {Carnot }}$ at 92.5 bar (94\% at 150 bar) against $95.4 \%$ for Carnot-type cycle at the same pressure. Then, the COP is still highly improved $(55 \%)$ when compared to conventional $\mathrm{CO}_{2}$ cycle.

\subsection{Expander efficiency}

In this section, simpler and conventional (Figure 3) designs isentropic expander efficiencies equal to $60 \%$ are assumed [6].

We notice, in Table 3, that an optimal high-pressure exists for both cycles: 122 bar with simpler design against 95 bar with conventional one. Therefore, the proposed design $\mathrm{COP}$ is more sensitive to the expansion efficiency.

Indeed, the simpler cycle HP is higher (122 bar) than that of the conventional design (95 bar). Then the expansion leads to higher work recovered and liquid quality at evaporator inlet, $+45 \%$ and $+17 \%$ respectively. Furthermore with expander efficiency diminution, the optimal HP decreases a lot with simpler design and increases in little proportion with conventional design, which impacts work-recovering expansion and cooling capacity.

Both COP decrease, by $14 \%$ and $10 \%$ respectively, when compared with corresponding ideal processes. However, the simpler cycle still keeps a large profit compared with usual cycle one $(+59 \%$ of COP).

\subsection{Compression cooling efficiency}

Lastly, we have to evaluate the non-isothermal compression impact on performances. An endoreversible compression is considered (Figure 7) as explained in section 3 but two aspects differ. Despite cooling compression, the compressor discharge temperature $\left(\mathrm{T}_{\mathrm{Dis}}\right)$ is higher than $\mathrm{T}_{\mathrm{HT}}$. Then a small gas-cooler is used to cool outlet compressor vapours from $T_{\text {Dis }}$ to $T_{\mathrm{HT}}$. The cooled compression is still assumed reversible, but it exchanges heat at $\mathrm{T}_{\mathrm{Dis}}$ with a heat source at $\mathrm{T}_{\mathrm{HT}}$.

Results for two discharge temperatures are given in Table 3.

Whatever the outlet compressor temperatures pinch, it exists an optimal high-pressure on the studied scale, which decreases as the outlet temperature increase: with $\mathrm{T}_{\text {Dis }}$ set at $50^{\circ} \mathrm{C}$, the optimal high-pressure is about 112 bar against 100 bar at $60^{\circ} \mathrm{C}$. It corresponds 
to COP equals to 4.59 and 4.15 respectively. Therefore, compared to the isothermal compression $(\mathrm{COP}=6.32), \mathrm{COP}$ decreases quickly with the temperature pinch increase. Although COP is sensitive to $\mathrm{T}_{\text {Dis }}$, it is still greatly higher than that of conventional cycle $\left(+21 \%\right.$ at $60^{\circ} \mathrm{C}$ and $34 \%$ at $\left.50^{\circ} \mathrm{C}\right)$, provided that $\mathrm{T}_{\text {Dis }}$ remains at acceptable values $\left(<60^{\circ} \mathrm{C}\right.$ in this case).

It has be noticed that for given expander efficiency, the volumetric capacity, the ratio $\&_{\mathrm{E}} / \&_{\mathrm{NET}}$ and $\left|\&_{\mathrm{Out}} / \&_{\mathrm{EV}}\right|$ are of the same order of magnitude for the three cycles (Table 3). The differences are due to the difference in high-pressure. A higher HP implies better cooling capacity because of increased liquid quality at evaporator inlet. Similarly, an increase in HP results in an increase of the recovered work at the expanders. However, ${ }_{\mathrm{E}} / \mathrm{N}_{\mathrm{NET}}$ depends on ${ }_{\mathrm{CP}}$ too. Hence, comparing the endoreversible and the simpler design, despites decrease by $6 \%$ of $\&_{\mathrm{E}}$ as the HP drops from 122 bar to 112 bar, ${ }_{\mathrm{E}} / \mathrm{NET}_{\mathrm{NP}}$ decreases by $19 \%$ as in the same time increased by $12 \%$.

\section{Conclusions}

From a thermodynamical point of view, the proposed Carnot-type cycle allows to reach close $\mathrm{COP}_{\text {Carnot }}$. Thus, it is possible to improve each conventional sub-critical and trans-critical cycles. However, the profit is not always so relevant according to the configuration.

With conventional sub-critical cycles, the condensation permits already to have high performances. Consequently, the Carnot-type cycle benefit gets only to $12 \%$ compared with the best conventional one. With cryocooling applications, as both cycle are based on cooling compression, the profit is not more substantial.

Concerning the $\mathrm{CO}_{2}$ trans-critical Carnot-type cycle, the expected gain is about $70 \%$ and still $65 \%$ with a simpler cycle. So that isothermal compression is relevant with $\mathrm{CO}_{2}$ cycles and it confirms that they need to have a cryogenics approach [11].

If expansion efficiency is taken into account (60\%), the profit is still about $60 \%$ despite a more important sensitivity to this parameter, compared with the conventional cycle. Finally, the compressor heat extraction has to be efficient. For a $20 \mathrm{~K}$ at compressor discharge, it is suitable to put a gas-cooler, then COP decreases by $24 \%$ compared to the isothermal case but is still improved by $21 \%$ compared to the conventional cycle COP or $34 \%$ if pinch is reduced to $10 \mathrm{~K}$.

These encouraging results prove that the isothermal compression is relevant for $\mathrm{CO}_{2}$ trans-critical cycle, according to an efficient cooling during compression. Furthermore, compression enhancement is the main way to improve significantly the conventional COP cycle, as an increase in expander efficiency will have only a small impact on the performances.

Further work will consist in investigating possible ways to get an efficient compression cooling. Consequently, we have to explore different compression designs taking into account heat transfer phenomena. 


\section{References}

[1] Lee YS, Liu CH, Chen TW. Thermodynamic analysis of optimal condensing temperature of cascade-condenser in $\mathrm{CO}_{2} / \mathrm{NH}_{3}$ cascade refrigeration systems. Int. J. Refrigeration 2006; 29; 1100-1108.

[2] Klein SA, Reindl DT, Brownell K. Refrigeration system performance using liquidsuction heat exchangers. Int. J. Refrigeration 2000; 23; 588-596.

[3] Sankarlal T, Mani A. Experimental investigations on ejector refrigeration system with ammonia. Renewable Energy 2006; 32; 1403-1413.

[4] Selvaraju A, Mani A. Experimental investigations on R-134a vapour ejector refrigeration system. Int. J. Refrigeration 2006; 29; 1160-1166.

[5] Kim MH, Pettersen J, Bullard CW. Fundamental process and system design issues in $\mathrm{CO}_{2}$ vapour compression systems. Progress in Energy and Combustion Science 2004; $30 ; 119-174$.

[6] Robinson D, Groll E. Efficiencies of transcritical $\mathrm{CO}_{2}$ cycles with and without an expansion turbine. Int. J. Refrigeration 1998, 21; 577-589.

[7] Meunier F. Refrigeration Carnot-type cycle based on isothermal vapour compression. Int. J. Refrigeration 2006; 29; 155-158.

[8] Feidt M, Costea M, Petre C, Petrescu S. Optimization of the direct Carnot cycle. Applied Thermal Engineering 2007; 27; 829-839.

[9] Bonjour J, Bejan A. Optimal distribution of cooling during gas compression. Energy 2006; 31; 409-424.

[10] Toublanc C, Clausse M, Terrier MF, Meunier F. $\mathrm{CO}_{2}$ Carnot-type cycle based on isothermal vapour compression. Proceedings of the $7^{\text {th }}$ IIR-Gustav Lorentzen Conference on Natural Working Fluids, 2006 May 28-31; Tronheim, Norway.

[11] Vaisman IB.COP Analysis of carbon dioxide cycles. ASHRAE Transactions 2002, 108; 252-262; USA. 


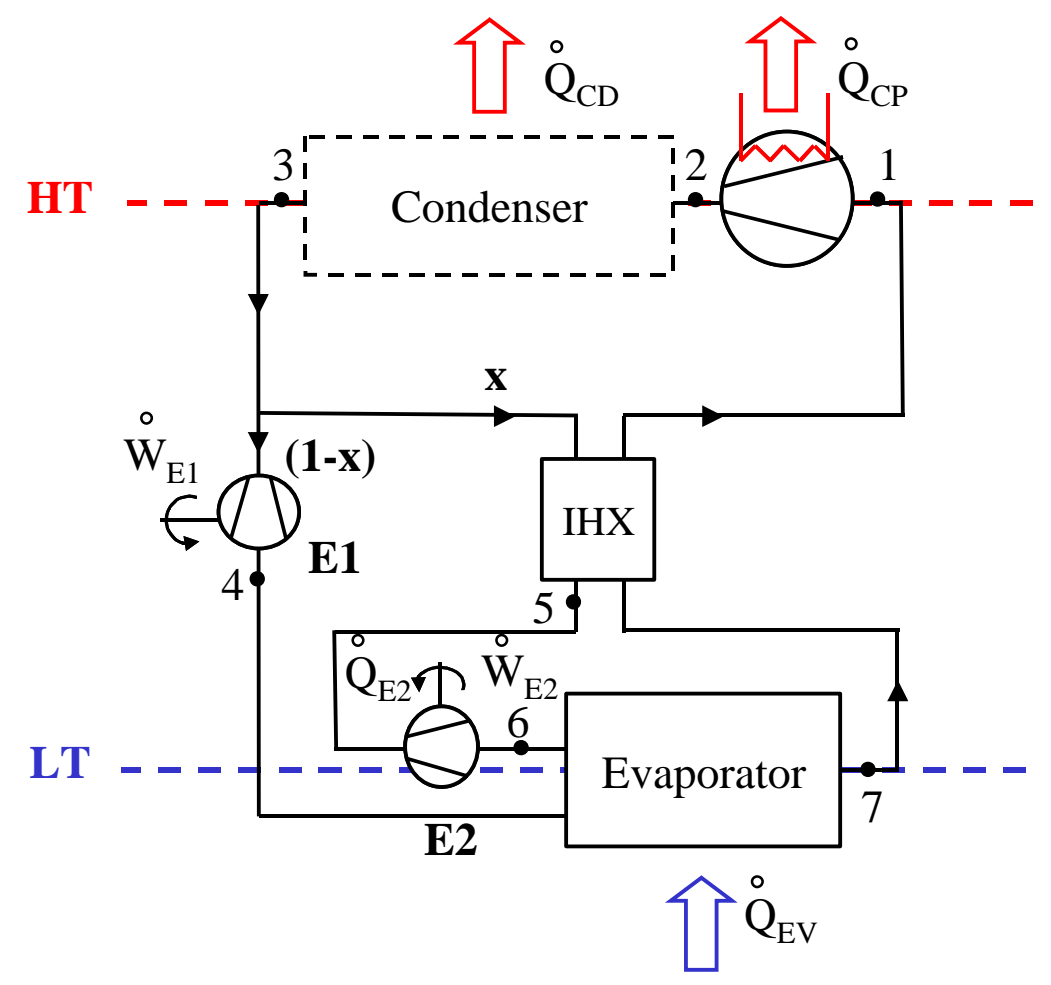

Figure 1: Ideal Carnot-type cycle. 


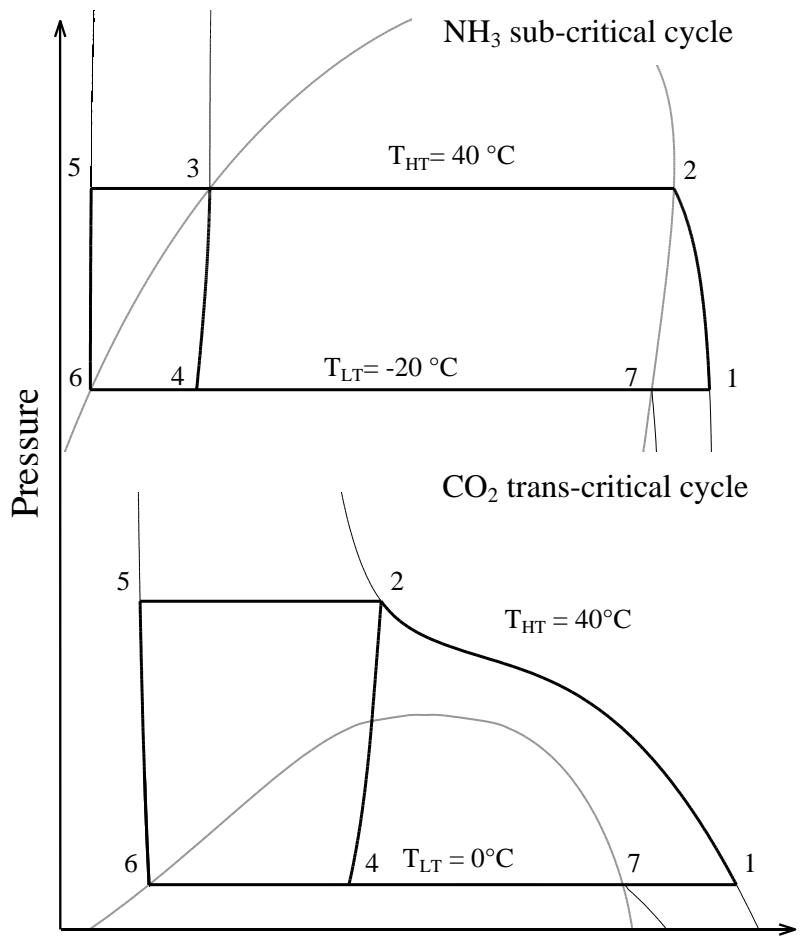

Enthalpy

Figure 2: Carnot-type cycle in $(\mathrm{h}, \mathrm{P}) \mathrm{NH}_{3}$ and $\mathrm{CO}_{2}$ diagrams. 


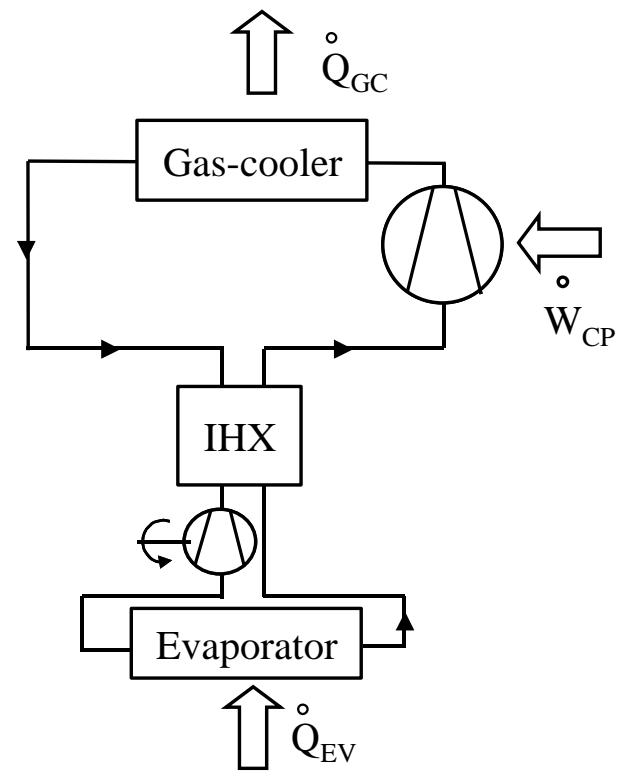

Figure 3: State of the art $\mathrm{CO}_{2}$ trans-critical cycle. 


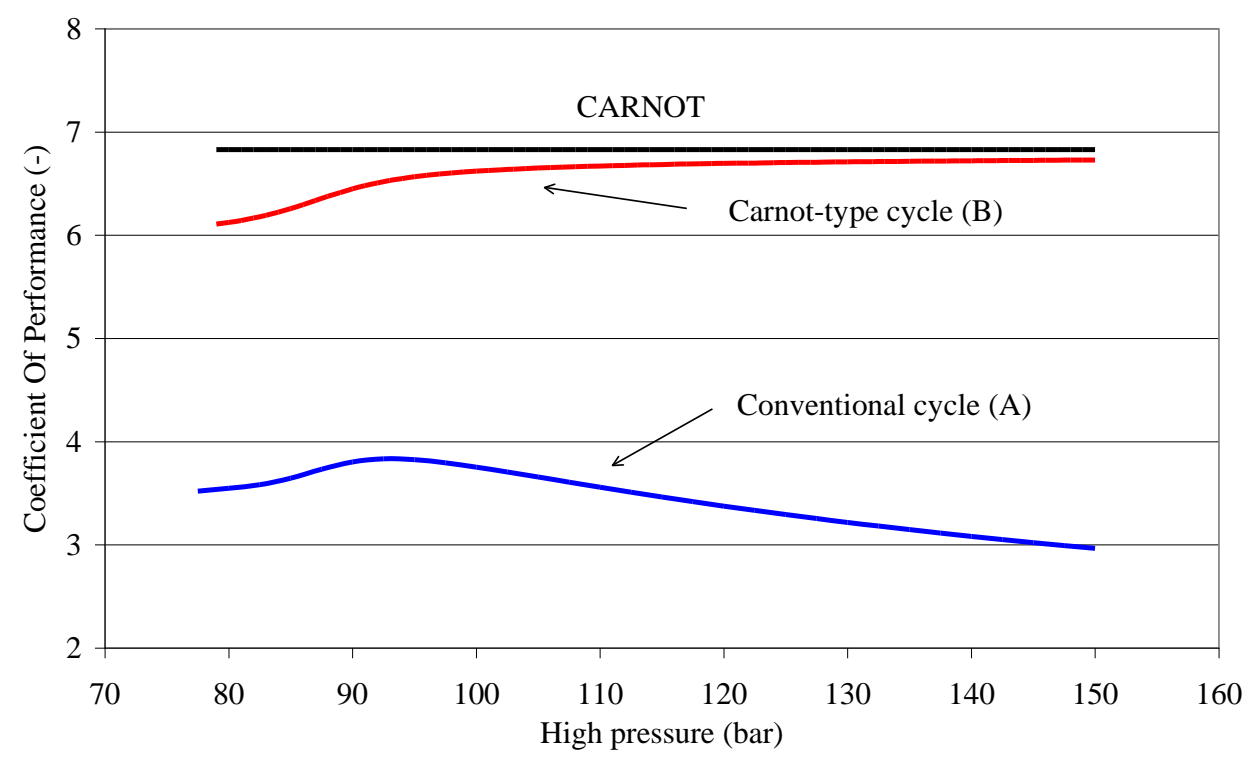

Figure 4: Evolution of COP vs. High-Pressure for both $\mathrm{CO}_{2}$ cycles. 


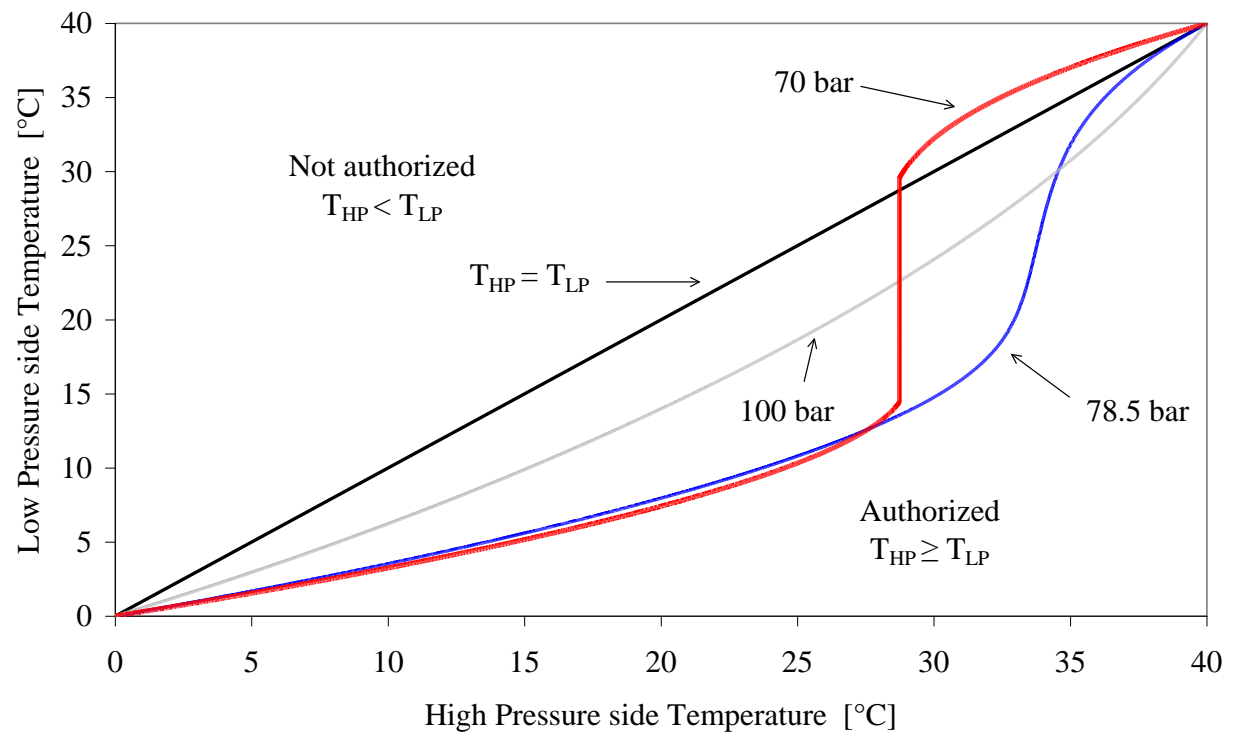

Figure 5: Both discretized IHX temperature evolutions. 


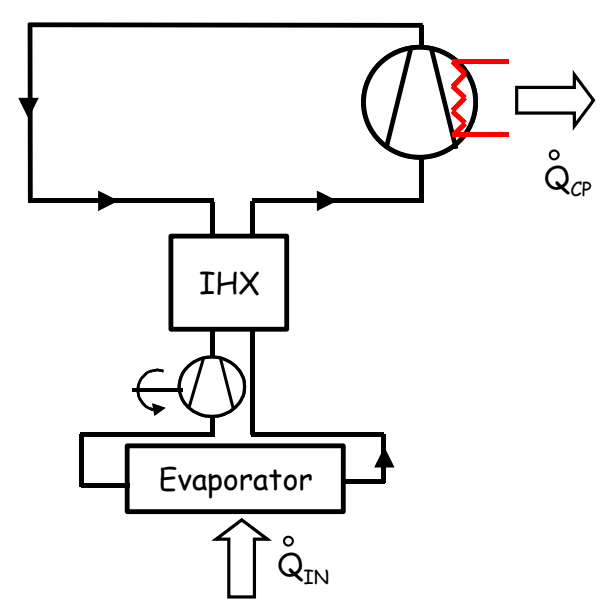

Figure 6: Simpler trans-critical cycle. 


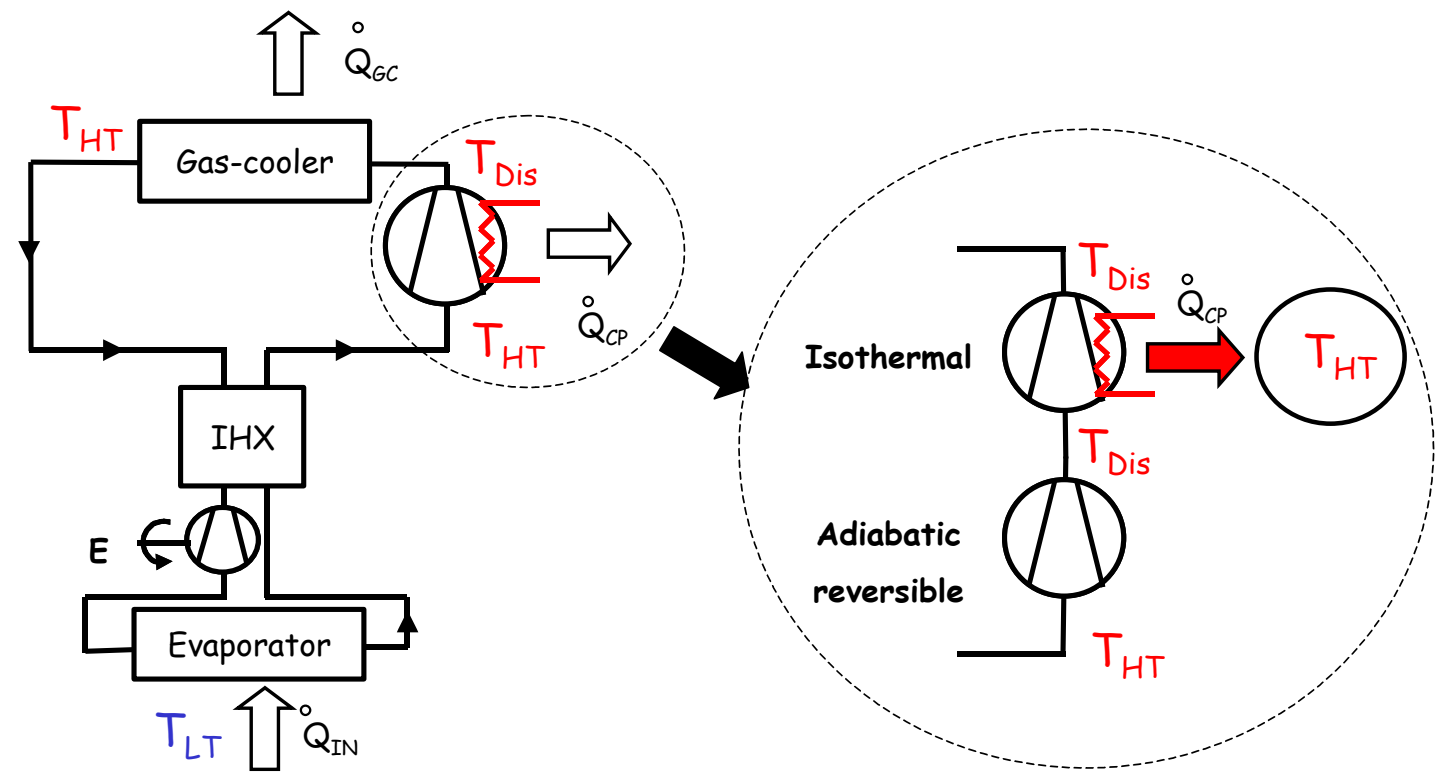

Figure 7: Endoreversible cooled compression design. 


\section{Figure captions}

Figure 1: Ideal Carnot-type cycle.

Figure 2: Carnot-type cycle in $(\mathrm{h}, \mathrm{P}) \mathrm{NH}_{3}$ and $\mathrm{CO}_{2}$ diagrams.

Figure 3: State of the art $\mathrm{CO}_{2}$ trans-critical cycle.

Figure 4: Evolution of COP vs. High-Pressure for both $\mathrm{CO}_{2}$ cycles.

Figure 5: Both discretized IHX temperature evolutions.

Figure 6: Simpler trans-critical cycle.

Figure 7: Endoreversible cooled compression design. 


\section{Tables}

Table 1: Comparison of Carnot-type and conventional $\mathrm{NH}_{3}$ cycles.

\begin{tabular}{lrccc}
\hline Cycle & & $\begin{array}{c}\text { Carnot-type } \\
\text { cycle }\end{array}$ & $\begin{array}{c}\text { Conventional } \mathrm{NH}_{3} \text { cycles } \\
\text { Throttling } \\
\text { device (A) }\end{array}$ & Expander (B) \\
\hline $\mathrm{COP}_{\mathrm{Carnot}}$ & $(-)$ & & 4.22 & \\
$\mathrm{COP} / \mathrm{COP}$ & $(\%)$ & 99.8 & 77.7 & 178.7 \\
Volumetric capacity & $\left(k J \cdot m_{\text {Suc. }}^{-3}\right)$ & 1518 & 1679 & 10 \\
$\left|\&_{\mathrm{E} 1}+\&_{\mathrm{E} 2}\right| / \&_{\mathrm{NET}}$ & $(\%)$ & 6 & - & 127 \\
$\mid\left(\&_{\mathrm{CP}}+\&_{\mathrm{CD}}\right) / \&_{\mathrm{EV}}$ & $(\%)$ & 124 & 130 & \\
\hline
\end{tabular}


Table 2: Comparison of Carnot-type and conventional $\mathrm{CO}_{2}$ cycles.

\begin{tabular}{|c|c|c|c|}
\hline Cycle & & Carnot-type cycle & Conventional $\mathrm{CO}_{2}$ cycle \\
\hline $\mathrm{COP}_{\text {Carnot }}$ & $(-)$ & & \\
\hline $\mathrm{HP}$ & (bar) & & \\
\hline $\mathrm{COP} / \mathrm{COP}_{\text {Carnot }}$ & $(\%)$ & 95.4 & 56.1 \\
\hline Volumetric capacity & $\left(k J \cdot m_{S u c .}^{-3}\right)$ & 11769 & 11633 \\
\hline $\mid w_{E 1}^{\&}+w_{E 2}^{\&} / w_{N E T}$ & $(\%)$ & 49 & 25 \\
\hline$\left|\&_{\text {OUT }} / \&_{E V}\right|$ & $(\%)$ & 115 & 126 \\
\hline
\end{tabular}


Table 3: $\mathrm{CO}_{2}$ cycles degradation.

\begin{tabular}{|c|c|c|c|c|c|}
\hline \multirow{3}{*}{ Cycle } & \multirow{3}{*}{$\begin{array}{c}\text { Conventional } \\
\text { cycle } \\
\eta_{\text {EXP }} \\
60 \% \\
\end{array}$} & \multicolumn{2}{|c|}{ Simpler cycle } & \multirow{2}{*}{\multicolumn{2}{|c|}{$\begin{array}{c}\text { Endoreversible cycle } \\
\eta_{\text {EXP }} 60 \%\end{array}$}} \\
\hline & & $\eta_{\text {EXP }}$ & $\eta_{\mathrm{EXP}}$ & & \\
\hline & & $100 \%$ & $60 \%$ & $\Delta \mathrm{T}_{\text {Dis }} 10 \mathrm{~K}$ & $\Delta \mathrm{T}_{\text {Dis }} 20 \mathrm{~K}$ \\
\hline $\begin{array}{l}\mathrm{COP}_{\text {Carnot }} \\
(-)\end{array}$ & & & 6.83 & & \\
\hline $\begin{array}{l}\mathrm{HP} \\
(\text { bar })\end{array}$ & 95 & 122 & 122 & 112 & 100 \\
\hline $\begin{array}{l}\mathrm{COP} / \mathrm{COP} \text { Carnot } \\
(\%)\end{array}$ & 50.2 & 92.5 & 79.8 & 67.2 & 60.7 \\
\hline $\begin{array}{l}\text { Volumetric capacity } \\
\left(k J \cdot m_{S u c .}^{-3}\right)\end{array}$ & 11910 & 14242 & 13940 & 13533 & 12628 \\
\hline
\end{tabular}




\begin{tabular}{|c|c|c|c|c|c|}
\hline $\begin{array}{l}\left|\mathbb{E}_{\mathrm{E}}\right| / \mathbb{N}_{\mathrm{NET}} \\
(\%)\end{array}$ & 12.2 & 33.4 & 17.7 & 14.4 & 13.5 \\
\hline $\begin{array}{l}\left|\mathcal{Q}_{\text {OUT }} / \mathcal{Q}_{\mathrm{EV}}\right| \\
(\%)\end{array}$ & 130 & 116 & 118 & 122 & 124 \\
\hline
\end{tabular}

